\title{
AVALIAÇÃO GLOBAL DO ENSINO MÉDICO BRASILEIRO: INTERESSES DOS ATORES ENVOLVIDOS
}

(D) RAFAEL BARBOSA DA SILVA BICA'

(D) GEORGE EDWARD MACHADO KORNIS"

\author{
Universidade do Estado do Rio de Janeiro (UERJ), Rio de Janeiro-RJ, Brasil; \\ rafael_bica@yahoo.com.br \\ " Universidade do Estado do Rio de Janeiro (UERJ), Rio de Janeiro-RJ, Brasil; \\ gkornis@gmail.com
}

\section{RESUMO}

O artigo estuda os interesses da corporação médica, da comunidade acadêmica e dos representantes do poder Executivo na estrutura da avaliação sistêmica do ensino médico brasileiro. Mostra-se que a corporação médica tende a apoiar avaliações de viés mais regulatório, contrapondo-se aos interesses da comunidade acadêmica. Argumenta-se que os representantes do poder Executivo sofrem demandas mutuamente antagônicas e que tensionam suas políticas: expandir a rede de ensino médico e regular sua qualidade. Conclui-se que a configuração assumida pelos sistemas de avaliação do ensino médico depende da articulação política dos atores envolvidos, da força das demandas sociais sobre o tema e do equilíbrio entre as prioridades governamentais de expansão do ensino médico e regulação de sua qualidade.

PALAVRAS-chave FORMAÇÃO MÉdICA • AVALIAÇÃO DO ENSINO SUPERIOR • GRUPO DE INTERESSES. 


\section{EVALUACIÓN GLOBAL DE LA EDUCACIÓN MÉDICA BRASILEÑA: INTERESES DE LOS ACTORES INVOLUCRADOS}

\section{RESUMEN}

El artículo estudia los intereses de la corporación médica, de la comunidad académica y de los representantes del poder Ejecutivo en la estructura de la evaluación sistémica de la educación médica brasileña. Se muestra que la corporación médica tiende a apoyar evaluaciones de sesgo más regulatorio y se contrapone a los intereses de la comunidad académica. Se argumenta que los representantes del poder Ejecutivo sufren demandas recíprocamente antagónicas y que tensionan sus políticas: expandir la red de educación médica y regular su calidad. Se concluye que la configuración asumida por los sistemas de evaluación de la educación médica depende de la articulación política de los actores involucrados, de la fuerza de las demandas sociales sobre el tema y del equilibrio entre las prioridades gubernamentales de expansión de la educación médica y la regulación de su calidad.

PALABRAS CLAVE FORMACIÓN MÉDICA • EVALUACIÓN DE LA EDUCACIÓN SUPERIOR • GRUPO DE INTERESES.

\section{GLOBAL EVALUATION OF BRAZILIAN MEDICAL EDUCATION: INTERESTS OF THE ACTORS INVOLVED}

\section{ABSTRACT}

The article discusses the interests of the medical corporation, the academic community and representatives of the executive branch in the systemic evaluation structure of Brazilian medical education. It shows that the medical corporation tends to support evaluations with a more regulatory bias, contrasted with the interests of the academic community. It argues that the representatives of the executive branch are subjected to mutually antagonistic demands that put pressure on their policies: to expand the medical education network and to regulate its quality. The article concludes that the configuration assumed by the medical education evaluation systems depends on the political articulation of the actors involved, on the strength of the social demands on the topic, and on the balance between governmental priorities for the expansion of medical education and the regulation of its quality.

KEYWORDS MEDICAL TRAINING • HIGHER EDUCATION EVALUATION • STAKEHOLDERS. 


\section{INTRODUÇÃO}

Nas últimas décadas, o maior interesse da sociedade brasileira pela qualidade do ensino médico no país refletiu-se na proposição de diversos modelos para sua avaliação e no debate sobre a introdução de um exame de licenciamento em medicina (ELM) para os recém-formados. Alguns fenômenos recentes, de alcance global, contribuem para isso.

Swanson e Roberts (2016) descrevem a tendência mundial de crescimento do número de escolas médicas e, como consequência, dos temores generalizados sobre a queda na qualidade do ensino. No Brasil, país em que os governos federais vêm adotando, sob oposição da comunidade acadêmica e da corporação médica, políticas de estímulo à expansão de vagas nas redes pública e privada (CUNHA, 2003; NEUTZLING JUNIOR; OLIVEIRA; SHENEMANN, 2006), o total de escolas médicas cresceu 231\% entre 1994 e 2015 (SCHEFFER, 2015).

A maior mobilidade internacional da força de trabalho, por sua vez, tem motivado no Brasil questionamentos sobre os usos do Exame Nacional de Revalidação de Diplomas Médicos Expedidos por Instituição de Educação Superior Estrangeira (Revalida) - um ELM para médicos formados fora do país - e sobre a capacitação destes para exercer a medicina em território nacional. Essa discussão, que tem envolvido primordialmente as associações médicas e representantes do poder Executivo federal (CONCEIÇÃO; REAL, 2015), também é um fenômeno internacional e, como apontam Swanson e Roberts (2016) ao analisarem os critérios de licenciamento em diferentes países, está longe de um consenso.

Além disso, estudos recentes (MCCRORIE; BOURSICOT, 2009; MCMANUS et al., 2008) mostram variações no desempenho dos egressos de diferentes escolas médicas do Reino Unido em testes padronizados de conhecimentos teóricos. Esses resultados, observados em um país cuja qualidade do ensino é considerada elevada e relativamente uniforme, têm desafiado a ideia de que as escolas médicas podem avaliar seus estudantes adequadamente sem a interferência de um agente regulador externo.

Finalmente, Irvine (2006) argumenta que o caráter mais consumista da prestação de serviços médicos nas sociedades contemporâneas, aliado à maior divulgação de falhas no atendimento à população, vem pressionando a corporação médica a exigir, das universidades e do Estado, garantias de qualidade na formação dos profissionais e, por vezes, tentar assumir o controle sobre os seus processos de avaliação. No caso brasileiro, pode-se argumentar que a exigência de um "selo de garantia” para os profissionais, dentro dessa lógica mais consumista, também recai sobre os representantes do diversificado sistema de saúde suplementar que atende às camadas de maior poder aquisitivo (SCHEFFER, 2015). Tal pressão fica evidente, no país, ao se analisar o grande aumento em processos judiciais contra médicos em anos recentes (CAMBRICOLI, 2015). 
Em conjunto, na visão de Swanson e Roberts (2016), esses fatores fortalecem os argumentos em favor da introdução dos ELMs como instrumento de regulação externa - fenômeno que ocorreu recentemente em países como Alemanha e Suíça e que está em curso no Reino Unido, onde uma entidade médica nacional (o General Medical Council) decidiu em favor de sua implementação a partir de 2023.

No caso brasileiro, destacam-se também, como causas recentes para o maior interesse pela avaliação nacional do ensino médico, a definição, pela Constituição de 1988, do Sistema Único de Saúde (SUS) como ordenador da formação de profissionais para a saúde e a vigorosa expansão, desde então, do acesso da população à atenção primária pela estratégia de saúde da família (PAIM et al., 2011). Com isso, o atrelamento da educação médica às demandas do mercado de trabalho tornou-se um objetivo formal do Estado brasileiro, indicando que ela poderia se tornar objeto de maior regulação externa - o que se efetivou pela elaboração, em 2001 e 2014, das Diretrizes Curriculares Nacionais (DCNs) dos cursos de Medicina - e de novas formas de avaliação.

\section{MOTIVAÇÕES E OBJETIVOS}

Como se percebe, a regulação da qualidade do ensino médico brasileiro envolve áreas de potencial conflito entre os atores envolvidos. Em âmbito internacional, alguns autores têm analisado essas tensões, procurando entender melhor os interesses desses atores e as suas influências sobre os modelos de avaliação global vigentes em cada país.

Starr (1982) argumenta que, para a corporação médica, controlar a avaliação do ensino médico em nível sistêmico permite regular a entrada e a qualificação dos profissionais no mercado, facilitando a negociação de melhores condições de trabalho e minimizando danos à reputação da categoria. Para os professores universitários, trata-se de exercer seu trabalho sem interferência externa e estabelecer quais resultados ele deve produzir - uma autonomia que, segundo Freidson (1970), é o valor mais importante na construção de uma identidade profissional. Já Benveniste (2002) aponta que a autoridade para interpretar resultados de um modelo nacional de avaliação do ensino superior garante influência sobre a alocação de recursos públicos, a elaboração de políticas governamentais e a percepção pública sobre a qualificação profissional, interessando, assim, também a instituições de ensino superior (IES), empregadores do setor saúde (no caso da medicina) e ao próprio Estado.

A disputa entre esses atores remete ao conceito de "campo científico", definido por Pierre Bourdieu (GRENFELL, 2007) como o espaço de luta concorrencial pelo monopólio da autoridade sobre uma área do conhecimento - no caso, a prerrogativa de definir como se deve avaliar o ensino médico e quais devem ser as consequências 
dessa avaliação. A força de cada ator nesse campo, que define suas possibilidades de ação, é determinada pela sua autoridade científica sobre a matéria em questão e pelo seu prestígio social - seu "capital científico".

Alguns exemplos históricos ilustram como esse balanço entre os poderes de diferentes atores molda os processos globais de avaliação do ensino superior em diversos países. Benveniste (2002) demonstra que as diferenças entre Chile, Argentina e Uruguai nas estruturas e nas consequências práticas de seus modelos de avaliação associam-se diretamente aos objetivos políticos de cada Estado nacional, ao grau de articulação associativa dos demais grupos de interesse e à influência destes sobre as esferas de tomada de decisão sobre políticas públicas. No caso específico do ensino médico, Starr (1982) argumenta que o estabelecimento gradual de avaliações externas para regular a qualidade do ensino norte-americano a partir do final do século XIX, retirando a autonomia de gestão das escolas médicas, foi consequência da maior organização política da corporação médica, da sua conquista de prestígio ("capital científico") perante à sociedade da época e das demandas da sociedade civil e do mercado de trabalho. Contemporaneamente, Salter, Filippakou e Tapper (2016) indicam pressões semelhantes sobre a corporação médica britânica para explicar sua decisão favorável ao estabelecimento de um ELM no Reino Unido. Portanto, quando análises sobre o equilíbrio de poder entre distintos atores são contextualizadas social e historicamente, torna-se possível avaliar as prováveis direções futuras que os sistemas de avaliação deverão seguir.

Dessa forma, o objetivo principal do presente trabalho é caracterizar os interesses dos atores envolvidos com o ensino médico brasileiro em relação à avaliação sistêmica de sua qualidade (não restrita às práticas de avaliação adotadas por IES em seus contextos individuais), discutindo que fatores contribuem para a sua gênese e como eles norteiam as condutas desses atores. Como objetivos secundários, pretende-se analisar como esses interesses vêm moldando as conformações atuais de nossos sistemas de avaliação do ensino médico e quais são, considerando nosso contexto histórico atual, as suas direções futuras mais prováveis.

\section{METODOLOGIA}

$\mathrm{Na}$ análise bibliográfica, ficou evidente que os atores mais diretamente envolvidos na discussão são os representantes da corporação médica (conselhos federal e regionais, além de outras associações de classe), da comunidade acadêmica (professores e IES) e do poder Executivo brasileiro (em particular, o Ministério da Educação MEC - e instâncias subordinadas, como o Instituto Nacional de Estudos e Pesquisas Educacionais Anísio Teixeira - Inep). Por essa razão, seus interesses são o foco desta pesquisa. Outros atores, como entidades estudantis, representantes do poder 
Legislativo e empregadores no setor saúde (como associações de hospitais e seguros privados de saúde), embora tenham interesses genuínos e, muitas vezes, manifestados claramente, não assumem historicamente o protagonismo da discussão e nem das ações a ela relacionadas.

Assim, procurou-se obter informações sobre os posicionamentos dos atores principais, em fóruns de discussão e documentos oficiais, a respeito de qual deve ser a estrutura das avaliações do ensino médico e que consequências seus resultados devem ter. Investigaram-se quais sistemas de avaliação esses atores têm proposto nas últimas décadas e suas características. Finalmente, foram pesquisadas as alianças que eles celebraram com outros grupos de interesse para fortalecer politicamente sua agenda própria sobre a avaliação. Em conjunto, acreditamos que esses dados permitem chegar à desejada caracterização dos interesses de cada ator.

Para a coleta dessas informações, realizaram-se buscas em bases de dados científicos (Biblioteca Virtual em Saúde - BVS, Scientific Electronic Library Online SciELO, Google Acadêmico), combinando os termos "avaliação”, "educação médica”, "ensino médico", “estudantes”, “escolas médicas”, “exame da ordem”, “exame de licenciamento", "Brasil” e "brasileiros". Posteriormente, acrescentaram-se os termos “Abem”, “ABMES”, “CFM”, “Cremesp”, “Conselhos Regionais”, “AMB”, “Fenam”, "Anasem”, “exame do Cremesp”, “teste de progresso”, “Revalida”, “Saeme”, “Cinaem”, "SUS" e "Diretrizes Curriculares Nacionais". Como algumas informações estavam em websites, buscou-se também pelo Google. Finalmente, foram examinadas algumas publicações: Revista da Abem, Cadernos da Abem, o jornal Medicina, do CFM, e o Jornal do Cremesp. Como o trabalho se propõe a analisar interesses contemporâneos sobre avaliação, optou-se por limitar a busca ao período que se inicia em 1988, ano de lançamento da Constituição Brasileira e de criação do SUS - referências essenciais para o presente debate.

Foram incluídas informações sobre o Revalida por se considerar que os interesses envolvidos no licenciamento de estudantes formados fora do Brasil assemelham-se aos relacionados à avaliação do ensino brasileiro e podem facilitar a compreensão de alguns posicionamentos. Analogamente, optou-se por não analisar os interesses envolvidos na aplicação dos concursos para programas de residência médica, por não afetarem o licenciamento dos recém-formados e nem os impedirem de se especializar por outras vias. Por conseguinte, as questões do controle sobre o número de profissionais e da certificação da sua capacitação, que são centrais a esta discussão, estão ausentes.

A identificação de interesses com base na análise desses dados, bem como dos seus fatores de gênese e das suas relações com as ações dos atores a respeito do tema da avaliação, depende em larga escala da interpretação dos autores. Tal processo não é livre de subjetividades e certamente é influenciado pelas vivências pessoais e profissionais nos campos da medicina e da saúde coletiva. Logo, embora 
consideremos que esses interesses existem independentemente da nossa percepção, nossa capacidade de descrevê-los é limitada pelo alcance das nossas interpretações. Por essa razão, pode-se dizer que a análise de dados aqui realizada ancora-se em um enfoque realista crítico, dentro de uma perspectiva teórica interpretativista e de uma epistemologia construtivista, seguindo o modelo proposto por Gray (2014).

Apresentamos os resultados da análise documental em duas etapas. Na primeira, mais descritiva, relacionamos os posicionamentos, sistemas de avaliação e alianças relevantes que os atores em questão celebraram no período estudado. Na segunda, mais analítica, desenvolvida na seção Discussão, fazemos a interpretação mais subjetiva, procurando identificar, nos dados, quais interesses parecem motivar cada ator. Também, analisamos como a construção histórica das identidades institucionais dos atores e o contexto social em que estão inseridos influíram na gênese de seus interesses e como estes, de acordo com o equilíbrio entre as forças políticas dos atores, direcionam a avaliação nacional do ensino médico brasileiro para os formatos vigentes. Finalmente, nas Conclusões, consideramos o caráter dinâmico desse equilíbrio de poderes, com todos os seus condicionantes, para discutir que mudanças estruturais os processos de avaliação do ensino médico poderão sofrer no futuro.

Para fortalecer a credibilidade dos achados, ambos os autores realizaram individualmente todas as etapas da análise dos dados com base no mesmo conjunto de informações coletadas. Em seguida, os dados descritivos e as análises interpretativas foram trianguladas entre os autores até que ambos concordassem sobre os resultados finais, um processo que exigiu múltiplas iterações até o seu término. Como o trabalho envolveu apenas análise documental e informações de domínio público, não foi necessário submeter o projeto ao comitê de ética. Ademais, não houve financiamento para a realização deste trabalho.

\section{RESULTADOS}

\section{A comunidade acadêmica}

Nas discussões sobre avaliação nacional do ensino médico brasileiro, a maior representante da comunidade acadêmica tem sido a Associação Brasileira de Educação Médica (Abem). A entidade tem defendido consistentemente o uso de testes seriados para os estudantes, com fins formativos, e de avaliações das escolas médicas com base em processos de autoavaliação. Defende, ainda, o protagonismo docente na condução desses processos.

A avaliação do estudante deve ser planejada e realizada prioritariamente por docentes, em particular os que foram capacitados para isso e os que atuam diretamente com o estudante. (ZEFERINO et al., 2009, p. 31) 
Avaliar em um único momento, no final de toda a formação, é uma estratégia de avaliação inadequada e anacrônica. A avaliação deve ser feita em vários momentos do curso médico, com variados instrumentos de avaliação, que possam medir a aquisição de conhecimentos, de habilidades e atitudes médicas. A avaliação deve ser formativa. (MARTINS, 2005)

Por outro lado, a Abem se opõe a avaliações externas e terminais de estudantes e escolas, à divulgação ampla dos resultados e ao seu uso para a tomada de decisões como diplomação ou descredenciamento, defendendo um foco apenas formativo. Exemplos dessa visão são a oposição ao Exame do Conselho Regional de Medicina do Estado de São Paulo (Cremesp), avaliação que busca medir a aptidão dos recém-formados ao exercício da medicina (MARTINS, 2005), e às propostas iniciais do MEC de dar aos resultados da Avaliação Nacional Seriada dos Estudantes de Medicina (Anasem) ampla divulgação e usos somativos (ABEM, 2016). A crítica da Abem ao cunho mais intervencionista da $2^{a}$ edição das DCN (BICA, 2018) também ilustra sua posição.

Os sistemas de avaliação defendidos pela Abem refletem essas ideias. A entidade organiza, desde 2012, a aplicação dos Testes de Progresso em âmbito nacional: são avaliações seriadas e formativas do conhecimento dos estudantes (BICUDO et al., 2014) que vinham sendo aplicadas esporadicamente no Brasil desde a década de 1990. Em relação às avaliações das escolas, destaca-se seu protagonismo na condução da Comissão Interinstitucional para a Avaliação do Ensino Médico (Cinaem), uma ampla iniciativa que se estendeu de 1991 a 2001 e se baseou nos preceitos defendidos pela entidade: autoavaliação institucional, divulgação limitada de resultados e ausência de ranqueamento (PIERUCCI, 2010). Posteriormente, a Abem usou a mesma base conceitual em outras iniciativas: é o caso do Sistema de Acreditação das Escolas Médicas (Saeme), implementado em 2016 com a cooperação do Conselho Federal de Medicina (CFM).

A entidade tem tido influência sobre instâncias públicas de elaboração de políticas educacionais. Sua centralidade na condução da Cinaem, em que se articulou com outras entidades para bloquear o avanço de propostas que não lhe interessassem (PIERUCCI, 2010), e sua bem documentada presença em comissões de ensino de conselhos médicos e do próprio governo (BICA, 2018) ilustram sua ação política. Além disso, a Abem tem historicamente atuado como "operadora" de programas do governo federal de estímulo a mudanças curriculares em escolas médicas (GONZALEZ; ALMEIDA, 2010).

As associações que representam especificamente as IES privadas, componentes relevantes da comunidade acadêmica brasileira, têm tido atuação mais discreta nas arenas públicas de discussão e deliberação próprias à avaliação do ensino médico. Nesta pesquisa, não foi identificada uma participação relevante de seus membros 
nos principais fóruns e congressos, nas audiências sobre projetos de lei envolvendo a matéria e na elaboração de novos sistemas de avaliação. A ação mais significativa ocorreu em 2015, quando o Sindicato das Mantenedoras de Ensino Superior conseguiu, judicialmente, impedir a obrigatoriedade do Exame do Cremesp.

Cabe ressaltar, porém, que a Associação Brasileira de Mantenedoras do Ensino Superior (ABMES), a instituição que congrega seus gestores, tem sido bastante atuante em proposições relativas à avaliação do ensino superior em geral, e sempre no sentido de limitar o alcance regulatório de seus resultados sobre questões como descredenciamento (ABMES, 2012). Mesmo nas raras ocasiões em que se manifestou a respeito da avaliação do ensino médico, a entidade optou por fazê-lo apenas em relação aos instrumentos empregados pelo Sistema Nacional de Avaliação do Ensino Superior (Sinaes), os quais não são específicos aos cursos de medicina (ABMES, 2015).

É possível que a atuação da ABMES na esfera do ensino médico privilegie estratégias como o lobby político. De qualquer forma, é notável perceber que, embora defendam essencialmente os mesmos tipos e alcances de avaliação, há pouco diálogo institucional formal entre a Abem e as representantes das IES privadas a respeito da matéria da avaliação do ensino médico.

\section{A corporação médica}

Entre as entidades médicas, o Cremesp tem sido o defensor mais sistemático de avaliações externas e do uso de seus resultados para embasar decisões sobre qualificação dos formandos, no modelo dos ELMs. Apesar disso, não se opõe às avaliações formativas e defende a complementaridade dos formatos. A entidade questiona o protagonismo das escolas médicas como avaliadoras.

A maioria das escolas médicas, internamente, não avalia corretamente seus estudantes [...]. Assim, se impõe a adoção de avaliações externas, obrigatórias e independentes, quer dos alunos, quer dos docentes e das Escolas. (GONÇALVES, 2009, p. 6)

Os resultados das avaliações [...] devem ter consequências [...] imediatas, não só para impedir que o aluno malformado ingresse no mercado de trabalho, mas também [...] para obrigar as escolas a se adequarem às necessidades do ensino. (GONÇALVES, 2009, p. 7)

Em linha com essas ideias, o exame do Cremesp vem sendo aplicado desde 2005 com o objetivo de aferir a aptidão dos formandos ao exercício da medicina (CREMESP, 2014). Como o exame nunca se tornou obrigatório, limitando seu impacto, o Cremesp busca alianças com empregadores da saúde privada e gestores de programas de residência médica para que ele se torne critério de aprovação ou contratação. Acordos com outros conselhos regionais (CRMs) do país têm sido celebrados para difundir a 
aplicação de provas nos seus moldes. Logo, o Cremesp tenta estabelecer pela via do mercado de trabalho o imperativo das avaliações terminais.

O Exame do Cremesp ganhou valor de mercado a partir de 2015, quando várias instituições passaram a considerar a avaliação como um dos critérios de seleção para contratação de médicos. (CREMESP, 2016a)

[...] várias instituições de ensino, secretarias do Estado de S. Paulo e do interior, federação das Unimeds e Associação Nacional de Hospitais Privados [...] apoiam a aplicação do Exame do Cremesp. A participação do formando no Exame está inclusive sendo considerada como critério para a seleção à Residência Médica e para o mercado de trabalho no Estado de São Paulo. (CREMESP, 2016b)

Já a postura do CFM sobre o uso das avaliações externas tem sido inconstante. Até recentemente, a entidade se opunha à ideia de um ELM para formandos das escolas médicas brasileiras. Por outro lado, sempre apoiou enfática e sistematicamente o emprego de uma prova com o mesmo formato e consequências (o Revalida) para os egressos de escolas médicas estrangeiras.

O Conselho Federal de Medicina é contra projetos que tentam criar um exame de ordem. "Defendemos que haja um processo de avaliação da formação do médico no Brasil sim, mas não como o exame de ordem. O processo avaliaria continuadamente as escolas médicas, o processo pedagógico e o produto, para que o estudante tenha a melhor formação possível". (CFM, 2008)

Durante os debates, o presidente do CFM propôs também criação de um exame para testar o conhecimento de médicos formados no exterior e barrar aqueles que não tiverem bom desempenho. Segundo ele, o Conselho não quer criar uma reserva de mercado para os médicos formados no país, mas assegurar que a profissão seja exercida dentro de um padrão de qualidade. (AMB, 2008)

O aparente paradoxo, porém, desfez-se nos últimos anos à medida que o CFM foi assumindo pontos de vista gradativamente mais favoráveis ao uso regulatório da avaliação no Brasil, o que culminou na declaração de apoio ao Projeto de Lei 165/2017 do Senado brasileiro (AGÊNCIA SENADO, 2018), que propunha a criação de um ELM e o colocava sob gestão do CFM.

Defendemos que os maus resultados (da Anasem) gerem consequências, como a não diplomação ou o fechamento do curso. - Lucio Flávio Gonzaga Silva, coordenador da Comissão de Ensino Médico do CFM. (CFM, 2017)

O coordenador da Comissão de Ensino Médico do Conselho Federal de Medicina (CFM), Lúcio Flávio Gonzaga Silva, declarou que o órgão também 
apoia integralmente a proposta (de instituir um exame de licenciamento) e as emendas apresentadas pelo relator da matéria, o senador Ronaldo Caiado (DEM-GO). (AGÊNCIA SENADO, 2018)

Durante todo o período, o CFM manteve apoio às avaliações seriadas e formativas de estudantes (CFM, 2012), assumindo postura (similar à do Cremesp) de defender a complementaridade dos modelos. Em relação às avaliações das IES, sua posição é vacilante: embora tenha se associado à Abem para implementar o Saeme nos moldes "formativos" por ela propostos, o CFM já defendeu usos mais regulatórios para as avaliações institucionais em diversos momentos de sua história, como por ocasião da Cinaem (PIERUCCI, 2010) e da própria Anasem (LIMA, 2017).

Entre as demais entidades médicas, a falta de consenso é geral. A Associação Médica Brasileira (AMB) evoluiu recentemente de uma postura de oposição para a defesa dos ELMs. Já a Federação Nacional dos Médicos (Fenam) tem mantido sua oposição. Quanto aos CRMs, divergências pronunciadas também se observam, com diversos estados se manifestando a favor ou contra os ELMs (BICA, 2018).

\section{O Estado brasileiro - representantes do poder Executivo}

Até recentemente, os representantes do poder Executivo brasileiro eram notavelmente ausentes da discussão sobre a avaliação do ensino médico, não apresentando posicionamentos ou iniciativas específicas a seu respeito. A partir da década de 1990, foram implementadas avaliações do ensino superior em geral, que também eram utilizadas para avaliar o ensino da medicina, com destaque para o Exame Nacional de Cursos (criado em 1995 na gestão de Fernando Henrique Cardoso e já extinto) e o Sinaes (criado em 2003 na gestão de Luiz Inácio Lula de Silva e ainda vigente). No entanto, não havia nesses momentos propostas de avaliação específica do ensino médico pelo Estado brasileiro.

Em diversos fóruns de discussão e audiências públicas para análise de projetos de lei envolvendo a matéria, não houve participação dos representantes do MEC. Esse aparente "desinteresse" pela questão persistiu até 2013, quando a proposta da Anasem (BRASIL, 2013), feita na gestão de Dilma Rousseff no contexto do lançamento do Programa Mais Médicos, marcou a primeira iniciativa do poder Executivo de avaliar mais diretamente o ensino médico brasileiro. Desde então, os posicionamentos de representantes do poder Executivo têm sido pouco claros, ora defendendo a avaliação terminal dos egressos, ora condenando-a em favor das avaliações formativas e seriadas.

Como resposta às críticas sobre a qualidade dos cursos, Henry Campos [o representante do MEC] afirmou achar "inevitável caminharmos para avaliação de egressos, contudo que seja feita de uma maneira responsável e madura". (CFM, 2013a) 
Os exames terminais [como o do Cremesp] responsabilizam unicamente o estudante por eventuais problemas no aprendizado, não gerando impacto para os processos de avaliação da instituição de ensino. - nota do MEC. (COLUCCI, 2015)

Essa ambiguidade refletiu-se no processo de regulamentação da Anasem. O governo de Rousseff, após ter inicialmente proposto a avaliação como uma modalidade seriada e formativa dos estudantes, tentou dar à Anasem usos claramente somativos na primeira portaria (BRASIL, 2016) que buscou normatizá-la, em abril de 2016. Diante de algumas reações contrárias, como da Abem, ela foi redefinida (já na gestão provisória de Michel Temer) como uma modalidade apenas formativa (INEP, 2016), cujos resultados teriam divulgação restrita - afastando a possibilidade de uso para fins de regulação. Ademais, apenas a primeira edição da prova (em 2016) foi aplicada, não tendo sido mantida pelas gestões seguintes. Na gestão atual, a ambiguidade parece persistir, com declarações do então ministro da Saúde favoráveis aos ELMs e do próprio presidente da República em oposição (AGÊNCIA BRASIL, 2018).

A postura dos governos brasileiros a respeito da regulação da entrada de médicos formados fora do Brasil também tem sido oscilante. Conceição e Real (2015) demonstram que, ainda na gestão de Lula da Silva, em 2010, foi implementado um projeto-piloto de avaliação que, a partir de 2011, tornou-se o Revalida - uma proposta de padronizar os critérios de admissão desses profissionais. O Revalida, embora não fosse ainda uma avaliação obrigatória, recebeu ampla adesão das universidades responsáveis pela validação dos diplomas estrangeiros e teve boa aceitação pelo CFM e outras entidades médicas (CFM, 2011). No entanto, por ocasião do lançamento do Programa Mais Médicos, em 2013, as regras para a validação foram flexibilizadas pelo poder Executivo (BRASIL, 2013), criando mecanismos para permitir o exercício da medicina em território nacional sem validação prévia de diploma estrangeiro. Tal resolução provocou veemente oposição das entidades médicas, que, com a liderança do CFM, impetraram ações judiciais (CFM, 2013b) contra o MEC para impedir sua efetivação.

Essa sequência de eventos lançou dúvidas sobre as motivações do poder Executivo ao criar marcos regulatórios para a revalidação: enquanto o CFM os defende com um discurso clássico de "garantias de qualidade" (muito semelhante ao usado pelo Cremesp para defender os ELMs no Brasil), é difícil definir se os últimos governos federais comungam desse objetivo ou se estão interessados em simplificar e acelerar os processos. É o que sugere na seguinte passagem da Portaria Interministerial (BRASIL, 2009) que criou o projeto-piloto do Revalida:

Estima-se existir no Brasil elevada demanda reprimida de revalidação de diplomas de curso médico obtidos no exterior e o atendimento 
é dificultado por várias razões. Não se identifica uma oferta regular de oportunidades de revalidação que possa atender ao fluxo de retorno ao país de brasileiros graduados em escolas médicas no exterior e as IES têm dificuldade de ampliar a sua capacidade de atendimento a essa demanda. (BRASIL, 2009, p. 14)

$\mathrm{Na}$ atual gestão do poder Executivo, algumas ambiguidades sobre a questão permanecem. Em 2019, Jair Bolsonaro sancionou a Lei n. 13.959, tornando obrigatória a aprovação no Revalida para a validação de diplomas estrangeiros. Diante de pressão política do CFM e de outras entidades médicas (CFM, 2019), foi vetada, no texto da mesma lei, a proposta de estender às IES privadas a prerrogativa de fazer a validação. Com isso, é possível identificar uma maior aproximação entre a atual gestão federal e as entidades médicas. Contudo, o próprio MEC (então sob o comando de Abraham Weintraub) propôs, no mesmo ano, no âmbito de um novo projeto de gestão universitária (o "Future-se"), a possibilidade de revalidação simplificada dos diplomas estrangeiros, sem a aplicação do Revalida - o que novamente produziu veemente oposição do CFM.

\section{DISCUSSÃO}

A análise dos posicionamentos da comunidade acadêmica, da corporação médica e do poder Executivo brasileiro em relação à avaliação do ensino médico no país deve ser feita à luz de alguns condicionantes históricos que facilitam sua compreensão.

No caso geral do Estado brasileiro, delineia-se um conflito entre duas demandas sociais distintas: a expansão das vagas no ensino superior e a maior regulação de sua qualidade. A demanda por regulação é comparativamente recente - e, em boa margem, exacerbada pelas políticas governamentais de expansão.

Desde a década de 1960, como demonstra Veras (1984), os governos federais brasileiros vêm adotando políticas de estímulo ao aumento de vagas no ensino superior e, em particular, no ensino médico. $\mathrm{O}$ autor argumenta que o objetivo maior, naquele momento, seria atender à demanda de uma classe média crescente e urbanizada por maior acesso ao ensino superior.

A partir da década de 1990, essas iniciativas se intensificaram nas gestões de Fernando Henrique Cardoso, Luiz Inácio Lula da Silva e Dilma Rousseff, por meio da criação de um arcabouço legal (CUNHA, 2003) e de programas de financiamento (NEUTZLING JUNIOR; OLIVEIRA; SHENEMANN, 2006) que facilitaram o estabelecimento de novas IES e o aumento de vagas naquelas já existentes, privilegiando especialmente as instituições de ensino privadas, que vêm desde então conhecendo vigorosa expansão - um processo que, segundo Cunha (2003, p. 58), configura uma verdadeira "aceleração da privatização do ensino superior". 
Alguns fatores adicionais contribuem para essa etapa mais recente da expansão. Como analisam Paim et al. (2011), o Brasil conheceu na segunda metade do século XX uma vigorosa transição demográfica: uma população que se tornou muito mais numerosa, urbana e idosa. Com isso, as demandas por serviços de saúde se multiplicaram e os postos de trabalho disponíveis para médicos nas redes pública e suplementar aumentaram vigorosamente, pressionando por uma maior oferta de profissionais qualificados. Nesse contexto, a expansão da atenção primária pelo país por meio da criação e regulamentação do SUS teve papel essencial.

Isso explicaria o histórico desinteresse (até recentemente) dos representantes do poder Executivo por avaliações mais rigorosas, que regulassem a qualidade do ensino e impusessem limites à desejada expansão por meio da reprovação dos formandos ou do descredenciamento das IES.

Todavia, a expansão decorrente dessas políticas provocou críticas e temores, de diversos setores da sociedade, sobre a baixa qualidade do ensino oferecido pelas novas escolas. Além disso, como analisa Benveniste (2002), a consolidação do processo de globalização capitalista na América Latina, a partir da década de 1990, reforçou uma percepção social mais utilitária da educação superior como meio de prover os recursos humanos necessários à condução do progresso econômico. Portanto, como ponderam Nunes, Fernandes e Albrecht (2014), a garantia de qualidade passa a ser uma questão central da gestão governamental sobre a educação superior.

É nesse contexto que surge e se consolida, na análise de Morosini, Oliveira e Bittar (2008), o "Estado avaliador", que assume o controle da avaliação do ensino superior e condiciona o recredenciamento das IES aos seus resultados - retirando das universidades uma prerrogativa clássica. Polidori (2009) demonstra que os modelos de avaliação propostos pelos governos federais brasileiros, desde a década de 1990, oscilam entre vieses mais ou menos regulatórios, talvez refletindo a tensão entre os interesses antagônicos de expandir e regular a qualidade da educação superior.

Essas tensões são percebidas ao se analisarem as características do Sinaes - o sistema governamental de avaliação do ensino superior nacional em vigência desde 2003. A Comissão Nacional de Avaliação do Ensino (Conaes), composta por membros do MEC, da comunidade acadêmica e de entidades que representam as IES, tem função consultiva, mas cabem ao Inep/MEC as decisões finais sobre sua estrutura, operação e usos.

Polidori (2009) destaca algumas contradições na estrutura do Sinaes. Em primeiro lugar, o sistema se propõe a promover o aprimoramento na qualidade do ensino nas IES avaliadas, mas usa os seus resultados para decidir sobre o recredenciamento delas. Com isso, o autor sugere uma falta de clareza em seus objetivos: pretende ser formativo, mas é usado para fins somativos. Isso se agrava à medida que a avaliação mistura métodos muito distintos, como a autoavaliação institucional, a 
avaliação externa e as notas dos estudantes no Exame Nacional de Desempenho dos Estudantes (Enade), para produzir um escore final de pouco valor psicométrico e que não avalia corretamente as dimensões essenciais à qualidade do ensino.

Além disso, em crítica à operacionalização do sistema pelo MEC, Nunes, Fernandes e Albrecht (2014) ponderam que o sistema é excessivamente centralizado e dependente de recursos humanos e técnicos muito superiores aos que o MEC possui para cumprir sua proposta de avaliar periodicamente os cursos envolvidos. Os autores concluem que o Sinaes assume um valor simbólico, à medida que o governo federal toma para si, em resposta às demandas da sociedade, a tarefa de avaliar o ensino superior sem que essa avaliação produza consequências relevantes sobre maus resultados e promovam as desejadas melhoras na qualidade do ensino superior. Dessa forma, o Sinaes expressa, em suas contradições, a encruzilhada em que se encontram os gestores de um poder Executivo que ainda não definiu, historicamente, se sua prioridade é manter o ritmo de expansão da rede de ensino superior ou regular sua qualidade com medidas restritivas sobre o credenciamento e a diplomação.

No caso particular do ensino médico, são também evidentes as demandas sobre os governos federais em dar à sociedade garantias da capacidade dos médicos recém-graduados - oriundas da sociedade civil e de setores economicamente relevantes como os representantes da saúde suplementar. Além disso, a vigorosa expansão nacional da rede pública de atenção primária e a responsabilidade estatal de prover atendimento de qualidade fortalecem o papel do Estado como "cliente" das escolas médicas, um ator que também necessita de tais garantias de qualidade. Não por acaso, essas demandas motivaram o governo federal, em 2013, a se colocar como um regulador mais efetivo da qualidade do ensino médico: com a criação da Anasem e, posteriormente, com a $2^{\mathrm{a}}$ edição das DCNs, em 2014.

Analogamente ao que se observa na formatação do Sinaes, a ambiguidade dos representantes do poder Executivo sobre seu eventual papel regulatório também se manifesta no caso do ensino médico: foi o que se observou no "vaivém" de portarias do MEC de regulamentação da Anasem e, finalmente, na sua descontinuação. Por enquanto, como ficou claro na regulamentação final da Anasem, é possível afirmar que o viés regulatório ainda não prevalece, o que pode ser atribuído tanto ao viés expansionista governamental, já analisado, como à influência política de atores selecionados (como a Abem e os representantes das IES privadas) e à capilaridade da comunidade acadêmica nas instâncias governamentais de execução de políticas educacionais. Esse último fator constitui, como ponderam Salter e Tapper (2002), um dos mais eficazes mecanismos de que a comunidade acadêmica dispõe para manter o controle sobre a gestão do ensino superior, uma vez que ela detém o conhecimento operacional dos processos - algo que, como demonstram Gonzalez e 
Almeida (2010), garantiu à Abem um protagonismo histórico na elaboração de políticas voltadas para o ensino médico brasileiro.

Finalmente, cabe observar que as tensões entre a expansão da força de trabalho médica e o controle sobre a qualidade da atuação de seus membros geram inconsistências internas e ambiguidades em gestões dos mais distintos espectros políticos e ideológicos. No caso das gestões de centro-esquerda de Luiz Inácio Lula da Silva e Dilma Rousseff, isso ficou evidente pelos movimentos antagônicos de criar um marco regulatório para a validação de diplomas estrangeiros no Brasil (o Revalida) e depois esvaziar seu alcance, ao criar mecanismos que permitiam a prática da medicina no Brasil por estrangeiros sem diploma validado. Já no caso da gestão de extrema-direita de Jair Bolsonaro, ações igualmente antagônicas do poder Executivo foram a sanção da obrigatoriedade do Revalida e a proposta (pelo MEC) de mecanismos de flexibilização dessa norma.

Em relação à comunidade acadêmica, suas posturas sobre avaliação representam tentativas de preservação da autonomia sobre o seu objeto de trabalho. Salter e Tapper (2002), em análise sobre os modelos de gestão do ensino superior britânico, descrevem um conflito entre um "modelo acadêmico", tradicionalmente calcado na autonomia universitária, e um "modelo econômico" que defende a regulação da gestão universitária por agentes externos para garantir à sociedade a produção dos recursos humanos necessários ao desenvolvimento econômico. Assim, à medida que o avanço das relações capitalistas de produção fortalece as motivações do "modelo econômico", a comunidade acadêmica desenvolve estratégias de defesa: uma das mais clássicas é a criação de sistemas próprios de avaliação que mantenham em seu seio o controle do processo avaliativo e evitem consequências indesejáveis para si.

Isso é precisamente o que caracteriza os sistemas propostos pela Abem, para estudantes e escolas, desde a década de 1990, momento histórico em que, como identifica Gomes (2006), avançam no Brasil o modelo de globalização capitalista e suas formas de produção. Suas características estruturantes são a autoavaliação, a divulgação limitada de resultados, a ênfase em avaliar processos (em vez de resultados) e a ausência de mecanismos de responsabilização clara pelos resultados obtidos. Benveniste (2002) descreve essas avaliações como "simbólicas", pois seus resultados não são usados para estruturar decisões sobre alocação de recursos públicos ou políticas educacionais. Por outro lado, a entidade se opõe a todas as formas de avaliação que retirem a autonomia da comunidade acadêmica e comprometam seu prestígio social e sua influência política: realizadas por agentes externos, com foco nos resultados, ampla divulgação pública e consequências potencialmente negativas para estudantes e escolas - como exemplo clássico, pode-se citar os ELMs.

Tal comportamento é compreensível à luz dos condicionantes históricos da formação da Abem e dos seus objetivos institucionais formais. A entidade 
congrega IES e indivíduos vinculados à educação médica - estudantes, professores e gestores, entre outros. Veras (1984) argumenta que sua fundação foi parte de um movimento internacional, iniciado na década de 1950, de "aglutinar pessoas e instituições com interesses na educação médica em entidades representativas" (BICA, 2018, p. 47). Gonzalez e Almeida (2010), por sua vez, descrevem os projetos de integração curricular que a entidade desenvolveu junto a entidades internacionais e governos brasileiros em diferentes momentos históricos. Veras (1984) postula que tais parcerias, ao conferirem à Abem legitimidade institucional e capacidade de operacionalizar programas, consolidaram sua influência nas esferas de decisão de políticas públicas.

Por outro lado, a identidade da Abem como instituição que procura preservar a primazia da comunidade acadêmica em processos relacionados ao ensino médico - e rejeitar concessões de poder a agentes externos - fica clara na sua "profissão de fé”. A Abem se propõe a "ser reconhecida como a principal protagonista de melhorias na educação médica brasileira, representante de seus associados, influenciando as políticas públicas de educação e saúde” (ABEM, 2017). No mesmo documento, a entidade coloca como objetivo a "presença marcada por participação, colaboração e/ou crítica, junto a órgãos de educação e saúde do país” e a "defesa dos interesses das instituições filiadas”.

Outro fator que contribui para a defesa da autonomia da comunidade acadêmica pela Abem é o que Bourdieu (GRENFELL, 2007) descreve como "contrato social" entre as universidades e a sociedade civil: o autor postula que, nas sociedades capitalistas contemporâneas, os diplomas universitários possuem valor semelhante aos títulos nobiliárquicos das sociedades feudais, constituindo-se meios para que indivíduos ocupem as posições de maior prestígio econômico e, desse modo, conquistem (ou preservem) um status social mais elevado. Segue desse raciocínio que a legitimidade social e o poder político das universidades dependem de sua capacidade de garantir a seus ingressantes tais prerrogativas.

Nesse sentido, existe uma interseção entre os interesses corporativos de professores universitários e os objetivos de gestores e proprietários das IES: para esses atores, a introdução de avaliações externas que retirem das universidades o poder de diplomar e licenciar seus estudantes é indesejável. Veras (1984) problematiza esse fenômeno, mostrando que, apesar de um discurso histórico de viés antimercantilista, a Abem, ainda assim, se alinha às demandas de caráter essencialmente financeiro daqueles grupos, aliando-se a eles na defesa dos modelos de avaliação que mais interessam a todos.

Tal dinâmica nos ajuda a compreender a "desconfortável aliança” entre a Abem e as associações que representam as mantenedoras das IES: defendem as mesmas avaliações, mas por razões muito distintas - com isso, não dividem as mesmas arenas 
de discussão e deliberação e atuam por vias e mecanismos separados. Nesse contexto, a liderança da Abem torna-se compreensível por meio do conceito de "capital científico" de Bourdieu: a entidade tem uma legitimidade social e operacional que a coloca como interlocutora mais qualificada para a defesa desses tipos de avaliação - e dificulta um diálogo institucional público e formal com as associações das mantenedoras, a quem lhe é politicamente pouco interessante dividir o protagonismo.

Em relação à corporação médica, dois padrões de comportamento caracterizam suas visões sobre modelos e usos da avaliação do ensino. O mais notável (e, à primeira vista, surpreendente) é a falta de consenso: as entidades federais (CFM, AMB, Fenam) e os CRMs apresentam opiniões bastante discordantes entre si. O outro aspecto relevante é a tendência recente, pelas entidades, de apresentar posturas mais favoráveis à regulação externa e à realização de ELMs. Os melhores exemplos são as "migrações" nas posições da AMB e do CFM, entidades que se opunham a essas ações e passaram a apoiá-las nos últimos anos.

Em princípio, tal discordância entre entidades médicas pareceria um contrassenso. Segundo Freidson (1970), uma das premissas para que uma profissão conquiste sua autonomia é o controle sobre a entrada de novos profissionais, definindo os conteúdos necessários ao seu aprendizado e os critérios de licenciamento. Logo, uma profissão "tende a perceber como ilegítima qualquer avaliação [...] que não parta de seus representantes" (BICA, 2018, p. 68). No caso da profissão médica, uma defesa unificada de avaliações de viés regulatório e externas à comunidade acadêmica seria o movimento mais previsível.

Um elemento-chave para entender esse comportamento aparentemente ilógico é a falta de unidade associativa. Labra (1993) argumenta que as entidades médicas nacionais nunca se reuniram em uma associação centralizada, com representação monopólica dos interesses da categoria. Starr (1982) pondera que essa descentralização associativa reduz seu poder político e sua capacidade de defender uma agenda corporativa comum - fatores que, na visão do autor, foram essenciais para que a profissão médica conseguisse, nos Estados Unidos do século XIX, ditar critérios de qualidade para o funcionamento e avaliação das escolas médicas.

Labra (1993) analisa que, desde a gênese do associativismo médico na década de 1920, a categoria nunca chegou a um consenso sobre a criação de uma representação unificada. Essa cisão concretizou-se quando, em 1945, o CFM e os conselhos regionais foram criados pelo governo federal e receberam atribuições limitadas ao credenciamento e controle da ética da profissão: a defesa dos direitos trabalhistas coube à Federação Nacional dos Sindicatos Médicos (precursora da Fenam) e a promoção de atualizações acadêmicas e do registro das sociedades de especialistas, à AMB.

Nessa divisão tricotômica, a pulverização da representação médica brasileira aumenta a competitividade de interesses setoriais que eventualmente sejam 
antagônicos aos da corporação como um todo. No contexto da regulação sobre a avaliação do ensino, Rubens Oliveira Martins (2006) ressalta que, além de gestores e proprietários das escolas médicas, deve-se considerar a influência política dos conselheiros (regionais e federais) que pertencem à comunidade acadêmica e que compartilham com ela interesses contrários à maior regulação.

A influência dos interesses "setoriais" fica muito clara quando, em contraposição, observamos as posições unificadas e veementes de todas as representações médicas na defesa de avaliações de viés regulatório (o Revalida) para a validação de diplomas estrangeiros. Nesse caso, estando ausente a competição dos interesses setoriais relacionados à preservação do prestígio das universidades nacionais e da comunidade acadêmica, a categoria consegue não apenas se unificar em torno de uma agenda mais alinhada aos seus interesses corporativos, como também exercer pressões políticas mais efetivas e influenciar decisões governamentais sobre elaboração de políticas públicas.

Há ainda um fator agravante, que reduz a gerência dos conselhos médicos sobre a formação profissional: a palavra final sobre a autorização de abertura de escolas, conteúdos curriculares e regras do primeiro licenciamento profissional pertence ao MEC. Embora o Conselho Nacional de Saúde (CNS), uma instância externa ao poder Executivo e composta por representantes da corporação médica e das empresas prestadoras de serviços de saúde, tenha poder opinativo sobre as deliberações do MEC, conforme regulamentado pelo art. 41 do Decreto n. 9.235/2017 (BRASIL, 2017), as decisões governamentais são definitivas e prevalecem. Essa conformação parece espelhar um fenômeno mais geral à educação superior brasileira, descrito por Nunes, Barroso e Fernandes (2008), de progressiva transferência de atribuições deliberativas originais do Conselho Nacional de Educação (CNE) para o MEC em matérias semelhantes de autorização e recredenciamento de IES - um processo que, segundo os autores, tornou-se claro a partir de 2001 e que pode refletir o interesse do Estado brasileiro em comandar, com maior autonomia, o processo de abertura de vagas no ensino superior.

Assim, o CFM e os CRMs não possuem, na prática, poder de regulação sobre a formação e o licenciamento profissional, sendo obrigados a seguir os requisitos estabelecidos pelo MEC. Com isso, a conquista de influência política e legitimidade social na área da avaliação nacional fica, muitas vezes, condicionada a alianças políticas com entidades que, em princípio, têm interesses corporativos fundamentalmente opostos - é o caso das colaborações entre o CFM e a Abem.

No entanto, e apesar da existência de interesses setoriais antagônicos, é clara a tendência geral das associações médicas a defender, cada vez mais, o uso de avaliações regulatórias e externas à comunidade acadêmica. Essa mudança pode ser elucidada quando se analisa o caso do Cremesp - entidade que tem sido sua 
maior proponente. São Paulo é o estado mais desenvolvido economicamente do país e possui a mais sofisticada rede de prestadores de serviços de saúde (IBGE, 2009). Por outro lado, o crescimento explosivo das escolas médicas no estado (SCHEFFER, 2015) leva à saturação do mercado de trabalho, especialmente nas regiões metropolitanas. Esses fatores, aliados à presença de um mercado consumidor exigente e de alto poder aquisitivo, colocam a categoria médica paulista sob demandas únicas de garantia de qualidade, dificultam a negociação de melhores condições de trabalho e contribuem para o aumento nos processos judiciais contra seus membros. Com isso, o estado reúne as maiores condições para estimular a defesa de um controle mais rígido da qualidade do ensino médico.

À medida que aumentam, em todo o país, a diversificação da rede de prestação de serviços médicos, a competição entre seus provedores e as exigências de um mercado consumidor mais bem informado e consciente dos seus direitos, reproduzem-se em graus crescentes as condições presentes em São Paulo. Intensificam-se as cobranças sobre o desempenho profissional dos médicos e, assim, as pressões para maior regulação da qualidade do ensino médico. Com isso, as entidades médicas passam a assumir posturas mais favoráveis às avaliações externas e, quando sua limitada influência política e gerencial não lhes permite implementá-las pelas vias "oficiais", ainda bastante obstaculizadas pelos interesses do Estado e da comunidade acadêmica, a tentar validá-las por alianças com atores, como empregadores do setor de saúde e gestores de programas de residências médicas.

\section{CONCLUSÕES}

A prevalência, no Brasil, de sistemas de avaliação com limitado poder de regulação sobre a qualidade do ensino médico parece se relacionar à influência política da comunidade acadêmica sobre as instâncias governamentais de elaboração de políticas educacionais, ao interesse predominante do poder Executivo em promover a expansão das vagas para o ensino superior e à falta de articulação corporativa da categoria médica.

No entanto, mudanças na história recente do país envolvendo o papel do Estado na organização dos serviços nacionais de saúde, o avanço de formas de organização produtiva que exigem maior regulação externa e a maior mobilização política da corporação médica em torno da questão vêm criando um novo equilíbrio de forças e poderão, em um futuro próximo, mudar a estrutura e o alcance dos sistemas de avaliação do ensino médico brasileiro.

A análise dessas tendências, porém, deve ser cuidadosa. Algumas das tensões subjacentes à discussão são estruturais e provocam, principalmente por parte dos governos federais, respostas ambivalentes e que parecem ser, em certo grau, 
transversais ao espectro político-ideológico de seus líderes. Além disso, o equilíbrio entre essas tensões é dinâmico e depende de fatores que são, de certo modo, imponderáveis, tais como quais articulações políticas prevalecerão entre os principais atores e como evoluirão as demandas da sociedade civil sobre a qualidade da medicina praticada no Brasil.

\section{REFERÊNCIAS}

AGÊNCIA BRASIL. Bolsonaro diverge de futuro ministro e diz que médico não precisa de exame como o da OAB. Congresso em Foco, Brasília, 25 nov. 2018. Disponível em: https://congressoemfoco. uol.com.br/saude/bolsonaro-diverge-de-futuro-ministro-e-diz-que-medico-nao-precisa-de-examecomo-o-da-oab/. Acesso em: 25 set. 2019.

AGÊNCIA SENADO. Exame de ordem para médicos divide opiniões em audiência pública. Senado Notícias, Brasília, 20 nov. 2018. Disponível em: https://www12.senado.leg.br/noticias/ materias/2018/11/20/exame-de-ordem-para-medicos-divide-opinioes-em-audiencia-publica. Acesso em: 25 set. 2019.

ASSOCIAÇÃO BRASILEIRA DE EDUCAÇÃO MÉDICA - ABEM. Posicionamento sobre a Avaliação Nacional Seriada dos Estudantes de Medicina (Anasem). 2016. Disponível em: https://abemeducmed.org.br/posicionamento-sobre-a-avaliacao-nacional-seriada-dos-estudantes-de-medicinaanasem/. Acesso em: 15 nov. 2018.

ASSOCIAÇÃO BRASILEIRA DE EDUCAÇÃO MÉDICA - ABEM. 0 que é a Abem. 2017. Disponível em: https://website.abem-educmed.org.br/sobre-a-abem/o-que-e-a-abem/. Acesso em: 10 jan. 2018.

\section{ASSOCIAÇÃO BRASILEIRA DE MANTENEDORAS DO ENSINO SUPERIOR - ABMES. ABMES} defende instituições particulares em análise sobre regulação do ensino superior. 24 maio 2012. Disponível em: https://abmes.org.br/noticias/detalhe/536/abmes-defendeinstituicoes-particulares-em-analise-sobre-regulacao-do-ensino-superior. Acesso em: 12 set. 2018.

ASSOCIAÇÃO BRASILEIRA DE MANTENEDORAS DO ENSINO SUPERIOR - ABMES. Consulta pública - Adequação do instrumento de avaliação de cursos de graduação presencial e à distância ao curso de graduação em medicina. Brasília, 2015. Disponível em: https://abmes.org.br/arquivos/ documentos/Inep_instrumento.pdf. Acesso em: 12 set. 2018.

ASSOCIAÇÃO MÉDICA BRASILEIRA - AMB. Audiência debate exame de habilitação para médicos. $J A M B$ - Jornal da Associação Médica Brasileira, São Paulo, ano 49, n. 1354, p. 12, jun./jul. 2008.

BENVENISTE, Luis. The political structuration of assessment: negotiating state power and legitimacy. Comparative Education Review, v. 46, n. 1, p. 89-118, Feb. 2002.

BICA, Rafael Barbosa da Silva. Exames de licenciamento em medicina: uma análise da discussão brasileira e internacional. 2018. 246 f. Tese (Doutorado) - Instituto de Medicina Social, Universidade do Estado do Rio de Janeiro, Rio de Janeiro, 2018.

BICUDO, Angélica Maria; MAFFEI, Claudia Maria Leite; ABBADE, Joelcio F.; HAFNER, Maria de Lourdes Marmorato Botta; YAZAKISUN, Sue. Avaliação do estudante: contribuição do teste de progresso. In: LAMPERT, Jadete Barbosa; BICUDO, Angélica Maria (org.). 10 anos das Diretrizes 
Curriculares Nacionais do Curso de Graduação em Medicina. Rio de Janeiro: Associação Brasileira de Educação Médica (Abem), 2014. p. 15-22.

BRASIL. Ministério da Educação. Ministério da Saúde. Portaria Interministerial n. 865, de 15 de setembro de 2009. Aprova o projeto piloto de revalidação do diploma de médico expedido por universidades estrangeiras e disponibiliza exame de avaliação com base em matriz referencial de correspondência curricular, com finalidade de subsidiar os procedimentos de revalidação conduzidos por universidades públicas. Diário Oficial da União, Brasília, 16 set. 2009.

BRASIL. Presidência da República. Lei n. 12.871/2013, de 22 de outubro de 2013. Institui o Programa Mais Médicos, altera as Leis n. 8745, de 9 de dezembro de 1993, e n. 6932, de 7 de julho de 1981, e dá outras providências. Diário Oficial da União, Brasília, 23 out. 2013.

BRASIL. Ministério da Educação. Portaria n. 168/2016. Institui a Avaliação Nacional Seriada dos Estudantes de Medicina. Diário Oficial da União, Brasília, 1 abr. 2016.

BRASIL. Presidência da República. Decreto n. 9.235/2017, de 15 de dezembro de 2017. Dispõe sobre o exercício das funções de regulação, supervisão e avaliação das instituições de superior e dos cursos superiores de graduação e de pós-graduação no sistema federal de ensino. Diário Oficial da União, Brasília, 18 dez. 2017.

CAMBRICOLI, Fabiana. Em 4 anos, o número de processos por erro médico cresce $140 \%$ no STJ. $O$ Estado de S. Paulo, São Paulo, 22 mar. 2015.

COLUCCI, Claudia. 91\% dos brasileiros querem "exame de ordem" para médicos, mostra pesquisa. Folha de S. Paulo, São Paulo, 22 out. 2015.

CONCEIÇÃO, Julie Christie; REAL, Giselle Cristina Martins. Revalidação de diplomas de cursos de graduação: uma análise da política em construção. Eccos - Revista Científica, São Paulo, n. 38, p. 129-144, 2015.

CONSELHO FEDERAL DE MEDICINA - CFM. CFM é contra exame de ordem para médicos, 5 jun. 2008. Disponível em: http://portal.cfm.org.br/index.php?option=com_content\&view=article\&id=74 30:\&catid=3. Acesso em: 25 set. 2015.

CONSELHO FEDERAL DE MEDICINA - CFM. CFM acompanha Revalida. Jornal Medicina, Brasília, n. 201, p. 6, 2011.

CONSELHO FEDERAL DE MEDICINA - CFM. CFM quer mais qualidade na formação. Jornal Medicina, Brasília, n. 215, p. 4, 2012.

CONSELHO FEDERAL DE MEDICINA - CFM. Fórum do CFM provoca reflexões sobre a formação do futuro médico. Eventos, Brasília, 2013a. Disponível em: http://www.eventos.cfm.org.br/index. php?option=com_content\&view=article\&id=21041\&Itemid=528. Acesso em: 15 nov. 2016.

CONSELHO FEDERAL DE MEDICINA - CFM. Confira a cronologia da crise na saúde. Jornal Medicina, Brasília, n. 222, p. 5, 2013b.

CONSELHO FEDERAL DE MEDICINA - CFM. Conselho investe em projeto de qualificação. Jornal Medicina, Brasília, n. 265, p. 5, 2017.

CONSELHO FEDERAL DE MEDICINA - CFM. Presidente Bolsonaro defende Revalida. Jornal Medicina, Brasília, n. 297, p. 9, 2019. 
CONSELHO REGIONAL DE MEDICINA DO ESTADO DE SÃO PAULO - CREMESP. Exame do Cremesp - Em sete anos, foram reprovados 46,7\% dos participantes. Exame do CREMESP: agora é obrigatório. São Paulo: Cremesp, 2014. p. 9-12.

CONSELHO REGIONAL DE MEDICINA DO ESTADO DE SÃO PAULO - CREMESP. Mercado reconhece a importância do exame. Jornal do CREMESP, São Paulo, n. 333, p. 10, 2016 a.

CONSELHO REGIONAL DE MEDICINA DO ESTADO DE SÃO PAULO - CREMESP. Avaliação acadêmica. CFM e CRMs realizam debate sobre o exame de egressos. 19 jul. 2016b. Disponível em: http://www.cremesp.org.br/?siteAcao=NoticiasC\&id=4129. Acesso em: 15 nov. 2016.

CUNHA, Luiz Antônio. O ensino superior no octênio FHC. Educação e Sociedade, Campinas, v. 24, n. 82, p. 37-61, 2003.

FREIDSON, Eliot. Profession of Medicine - A study of the sociology of applied knowledge. New York: Dodd, Mead and Company, 1970.

GOMES, Alfredo Macedo. Identidades discursivas público-estatal e privado-mercado: desafios teóricos ao campo da educação superior? In: SILVA JUNIOR, João dos Reis; OLIVEIRA, João Ferreira de; MANCEBO, Deise (ed.). Reforma universitária: dimensões e perspectivas. Campinas: Alínea, 2006. p. 157-170.

GONÇALVES, Henrique Carlos. A necessária reforma do ensino médico. In: CREMESP. Exame do Cremesp: uma contribuição para a avaliação do ensino médico. São Paulo: Cremesp, 2009. p. 4-7.

GONZALEZ, Alberto Duran; ALMEIDA, Marcio José. Movimentos de mudança na formação em saúde: da medicina comunitária às diretrizes curriculares. Physis - Revista de Saúde Coletiva, Rio de Janeiro, v. 20, n. 2, p. 551-570, 2010.

GRAY, David. Theoretical perspectives and research methodologies. In: GRAY, David (ed.). Doing research in the real world. London: Sage, 2014. p. 16-38.

GRENFELL, Michael. Pierre Bourdieu. London: Bloomsbury Academic, 2007.

INSTITUTO BRASILEIRO DE GEOGRAFIA E ESTATÍSTICA - IBGE. Pesquisa de Assistência Médico-Sanitária. 2009. Disponível em: https://www.ibge.gov.br/estatisticas-novoportal/sociais/ saude/2023-assistencia-medico-sanitaria/9067-pesquisa-de-assistencia-medico-sanitaria. html?\&t=resultados. Acesso em: 10 maio 2017.

INSTITUTO NACIONAL DE ESTUDOS E PESQUISAS EDUCACIONAIS ANÍSIO TEIXEIRA - INEP. Documento Básico - Avaliação Nacional Seriada dos Estudantes de Medicina. Brasília: Inep/MEC, 2016.

IRVINE, Donald. A short story of the GMC. Medical Education, n. 40, p. 202-211, 2006.

LABRA, Maria Eliana. Associativismo no setor saúde brasileiro e organizações de interesse do empresariado médico. Physis - Revista de Saúde Coletiva, Rio de Janeiro, v. 3, n. 2, p. 193-225, 1993.

LIMA, Carlos Vital Tavares Correa. As escolas de medicina no palco das ilusões. Jornal Medicina, Brasília, n. 263, p. 3, 2017.

MARTINS, Milton. A Associação Brasileira de Educação Médica e a proposta de instituição de um exame de habilitação para o exercício da medicina no Brasil. 2005. Disponível em: http://admabem.com.br/posicionamento_abem/posicao_exame_habilitacao.pdf. Acesso em: 3 mar. 2017. 
MARTINS, Rubens Oliveira. Uma abordagem sociológica acerca da expansão do ensino superior e a regulamentação de profissões no Brasil. Revista Múltipla, Brasília, v. 14, n. 20, p. 83-102, 2006.

MCCRORIE, Peter; BOURSICOT, Katharine A. M. Variations in medical school graduating examinations in the UK: are clinical competence standards comparable? Medical Teacher, n. 31, p. 223-229, 2009.

MCMANUS, Ian; ELDER, Andrew T.; CHAMPLAIN, Andre de; DACRE, Jane E.; MOLLON, Jennifer; CHIS, Liliana. Graduates of different UK medical schools show substantial differences in performances on MRCP (UK) Part 1, Part 2 and PACES examinations. BMC Medicine, v. 6, n. 5, 2008.

MOROSINI, Marília; OLIVEIRA, João Ferreira de; BITTAR, Mariluce. Educação superior no Brasil: 10 anos pós-LDB. Brasília: Instituto Nacional de Estudos e Pesquisas Educacionais, 2008.

NEUTZLING JUNIOR, João; OLIVEIRA, Renato Luiz Tavares; SHENEMANN, Daniela. Análise comparativa do Fies e do Prouni como meio de acesso do estudante à universidade particular - o caso da UCPEL em 2005. In: COLÓQUIO INTERNACIONAL SOBRE GESTÃO UNIVERSITÁRIA NA AMÉRICA DO SUL, 6., 2006, Blumenau. Anais [...]. Blumenau: UFSC, 2006. Disponível em: http:// repositorio.ufsc.br/xmlui/bitstream/handle/123456789/74628/t0099.pdf? sequence=1\&isAllowed=y. Acesso em: 14 mar. 2016.

NUNES, Edson; BARROSO, Helena Maria; FERNANDES, Ivanildo. O Conselho Nacional de Educação: trajetória, competências, deliberações e restrições ao futuro. Rio de Janeiro: Observatório Universitário, 2008. (Documento de Trabalho, n. 72).

NUNES, Edson; FERNANDES, Ivanildo; ALBRECHT, Julia. Regulação e ensino superior no Brasil. Rio de Janeiro: Observatório Universitário, 2014. (Documento de Trabalho, n. 112).

PAIM, Jairnilson; TRAVASSOS, Claudia; ALMEIDA, Celia; BAHIA, Ligia; MACINKO, James. The Brazilian health system: history advances and challenges. The Lancet, v. 377, n. 9779, p. 1778-1797, 2011.

PIERUCCI, Lucirleia Alves Moreira. Mecanismos de avaliação do ensino superior: avaliação e disputa pela formação médica legítima (1990-2005). Revista Espaço Acadêmico, Maringá, PR, v. 9, n. 107, p. 72-79, 2010.

POLIDORI, Marlis Morosini. Políticas de avaliação da educação superior brasileira: Provão, Sinaes, IDD, CPC, IGC e... outros índices. Revista Avaliação, Campinas, v. 14, n. 2, p. 439-452, 2009.

SALTER, Brian; FILIPPAKOU, Ourania; TAPPER, Ted. Expanding the English medical schools: The politics of knowledge control. London Review of Education, v. 14, n. 1, p. 23-32, 2016.

SALTER, Brian; TAPPER, Ted. The external pressure on the internal governance of universities. Higher Education Quarterly, v. 56, n. 3, p. 245-256, 2002.

SCHEFFER, Mário (coord.). Demografia médica no Brasil 2015. São Paulo: Departamento de Medicina Preventiva da Faculdade de Medicina da USP; Cremesp; CFM, 2015.

STARR, Paul. The social transformation of American medicine. New York: Basic Books Inc., 1982.

SWANSON, David; ROBERTS, Trudie. Trends in national licensing examinations in medicine. Medical Education, v. 50, n. 1, p. 101-114, 2016. 
VERAS, Renato. A ABEM e a visão à frente: características e limites de um discurso institucional. Revista Brasileira de Educação Médica, Brasília, v. 8, n. 1, p. 19-26, 1984.

ZEFERINO, Angélica M. Bicudo; TRONCON, Luiz E. de Almeida; HAMAMOTO FILHO, Pedro Tadao; COMES, Giovana Tucille; COELHO, Sawllus; GROWCHESC, Rafaela. Avaliação do estudante de Medicina. Cadernos ABEM, Rio de Janeiro, v. 5, p. 30-33, 2009.

\section{COMO CITAR ESTE ARTIGO}

BICA, Rafael Barbosa da Silva; KORNIS, George Edward Machado.

Avaliação global do ensino médico brasileiro: interesses dos atores envolvidos.

Estudos em Avaliação Educacional, São Paulo, v. 32, p. 1-25, e-07592, 2021.

DOI: https://doi.org/10.18222/eae.v32.7592 